\title{
Effects of a Trunk Stabilization Exercise with Gym Ball on Scapular Position for Patients with Arthroscopic Rotator Cuff Repair
}

Mi Young Jung', Young Uk Ryu²

${ }^{1}$ Yeungnam University Yeongcheon Hospital, Daegu; ${ }^{2}$ Department of Physical Therapy, College of Health Sciences, Catholic University of Daegu, Daegu, Korea

Purpose: The present study was to investigate effects of scapular position and pain on a trunk stabilization exercise with gym ball for patients with arthroscopic rotator cuff repair.

Methods: Subjects were patients after 2 weeks of rotator cuff repairs. Subjects were randomly assigned to conservative treatment group (CTG, $n=10)$ or trunk stabilization with gym ball group (SBG, $n=10)$, and participated one of those groups for 2 weeks. Measurements about pain and scapular position were assessed in before and after treatment programs.

Results: Pain reduced in both rest and night in SBG compared to CTG. In the case of scapular position, decreased scapular retraction (increased protraction) was found in CTG and vice versa in SBG. Reduced scapular anterior tilting was also found on SBG.

Conclusion: The present study showed that early performed trunk stabilization with gym ball could bring a scapular alignment that increases subacromial space and reduces pain. This suggests early trunk stabilization with gym ball programs to restore shoulder functions for patients with rotator cuff repair.

Keywords: Scapula, Stabilization exercise, Rotator cuff repair, Shoulder impingement

\section{INTRODUCTION}

어깨관절의 돌림근띠(rotator cuff) 손상은 60대 이상의 $10 \%$ (미국의 경우)가 가지고 있을 만큼 흔한 질환이다.1 돌림근띠를 손상시키는 여 러 원인들 중에서 부딪힘에 의한 손상을 충돌증후군(impingement syndrome)이라 한다. 어깨 충돌증후군은 일반적으로 팔을 어깨 높이 이상으로 올리는 동작을 할 때, 어깨 봉우리 아래 공간(subacromial space)과 부리봉우리 인대(coracoacromial ligament)에 돌림근띠가 부 딪쳐서 미세손상을 만들어 내게 되고 이러한 손상이 누적되어 발생 한다. ${ }^{2}$ 어깨의 이러한 부딪힘을 야기하는 원인은 다양하지만, 특별히 어깨뼈의 내밈(protraction)과 앞쪽 기울기(anterior tilting) 증가 등이 봉우리의 아래 공간을 좁혀 충돌을 일으키는 원인이 될 수 있다. ${ }^{3}$

지속된 충돌로 인하여 돌림근띠가 찢어질 경우, 외과적인 봉합이 필요할 수 있으며, 이는 돌림근띠의 연속성을 재형성시켜주어 어깨의 기능을 향상시키는 것이다. ${ }^{4}$ 일반적으로 돌림근띠 봉합 수술 후 외전
보조기를 4-6주간 착용하는데, 장기간의 착용은 등뼈(thoracic vertebra)의 뒤굽음(kyphosis)을 증가시킬 수 있다. ${ }^{5}$ 등뼈 뒤굽음은 어깨뼈 내밈과 어깨 안쪽 돌림(internal rotation)을 증가시킨다. ${ }^{6}$ 어깨뼈 내밈 은 작은 가슴근(pectoralis minor) 단축을 가져와 어깨뼈를 앞쪽으로 기울게 만든다. ${ }^{6.7}$ 이는 돌림근띠 봉합 이후에, 보존적인 관리로는 여 전히 자세적 문제로 충돌을 일으킬 수 있음 의미한다.

어깨뼈 정렬과 몸통 움직임은 상호작용을 한다. 몸통 근육의 강화 는 팔과 다리의 조화로운 움직임에 영향을 미치므로 인간의 움직임 에 있어 몸통의 근력이 뒷받침되어야 한다. ${ }^{\circ}$ 어깨뼈의 설정 중재를 통 한 자세조절 능력의 증진은 균형 및 보행에 효과적이며, ${ }^{9}$ 어깨뼈 안정 화가 뇌졸중 환자의 균형에 도움을 줄 수 있다는 보고도 있다. ${ }^{10}$ 또한 몸통의 협조 운동은 안정 시 어깨뼈의 위치나 움직임에 도움이 될 수 있는 것으로 보고되고 있다." 이러한 연구 결과들은 몸통 운동과 어 깨 관절 안정성은 관련이 있다는 것을 암시한다.

돌림근띠 파열의 빈도가 증가함에 따라 관절경에 의한 봉합술이
Received Jan 8, 2018 Revised Feb 7, 2018

Accepted Feb 22, 2018

Corresponding author Young Uk Ryu

E-mail ryuyounguk@gmail.com
Copylight (C) 2018 The Korea Society of Physical Therapy

This is an Open Access article distribute under the terms of the Creative Commons Attribution Non-commercial License (Http:// creativecommons.org/license/by-nc/4.o.) which permits unrestricted non-commercial use, distribution, and reproduction in any medium, provided the original work is properly cited. 
많이 이루어지고 있지만 수술 후 환자의 어깨관절 기능회복에 있어 여전히 다양한 프로그램이 제시되고 있다.1,12,13 기능적인 팔 움직임을 위해 어깨뼈와 몸통의 정렬에 대한 훈련의 중요성을 언급하고 있지 만 재활에 적용하는 시기는 불분명하며, 어깨관절에 대한 국한적인 치료 위주로 제시되고 적용되고 있다. ${ }^{14,15}$ 어깨 재활 프로그램에 있어 어깨 부위의 안정성은 중요한 요소로 여겨지고 있으나 재활 프로그 램에 있어 어깨뼈의 위치 변화를 살펴본 연구는 많지 않다. ${ }^{16}$ 본 연구 는 관절경하 돌림근띠 봉합술을 시행한 환자에게 수술 후 초기 단계 에서 짐볼(gym ball)을 이용한 몸통 안정화 운동의 적용이 어깨벼의 위치 변화와 통증에 미치는 영향을 알아보았다.

\section{METHODS}

\section{1. 연구 대상}

본 연구는 자기공명영상법(MRI)상에서 돌림근띠 파열이 확인되어 정 형외과 전문의로부터 관절경하 돌림근띠 봉합술을 받은 환자를 대상 으로 하였다. 본 연구 대상자의 선정조건은 다음과 같았다. 첫째, 돌림 근띠 파열 진단을 받고 수술 후 2주 경과한 자, 둘째, 돌림근띠 파열 크 기가 1-3 cm의 소, 중범위 이하 손상자, 셋째, 어깨관절 외전 보조기를 풀고 누운 자세와 선 자세를 유지할 수 있는 자, 넷째, 돌림근띠 봉합 술을 받은 어깨 외에 정형학적, 신경학적 병력이 없는 자, 마지막으로
통증에 대한 시각적 상사 척도표(visual analogue scale, VAS)을 이해하 고 사용할 수 있는 자로 하였다. 이러한 선정조건에 부합한 환자들 중 에서, 연구의 목적을 이해하고 자발적으로 연구 동의서에 서명한 환 자 20명을 대상으로 연구가 진행되었다. 연구는 보존적 치료군(conservative treatment group, CTG) $(\mathrm{n}=10)$ 과 짐볼을 이용한 몸통 안정화 운동을 적용시킨 운동군(stabilization exercise with gym ball, SBG) $(\mathrm{n}=10)$ 으로 나누어졌고, 대상자들은 두 그룹에 무작위로 지정되었다.

\section{2. 실험 절차}

두 그룹 모두 보존적 치료를 적용 받았으며, $\mathrm{SBG}$ 는 짐볼을 이용한 몸 통 안정화 운동을 추가적으로 적용 받았다. 두 그룹은 주 3 회, 2 주간 의 치료가 적용되었다. $\mathrm{CTG}$ 는 보존적 치료만 처치되었으며, 냉찜질 10 분, 적외선 15 분, 간섭파 치료 15 분, 지속적 수동 관절가동운동( $\mathrm{Ar}-$ tus-701S, Life-med, South Korea) 20 분이 적용되었다. SBG는 보존적 치 료 실시 후, $55 \mathrm{~cm}, 65 \mathrm{~cm}$ 의 짐볼(Togu $\left.{ }^{\circledR}, \mathrm{Germany}\right)$ 을 이용하여, 레그컬 (leg curl)1, 레그컬2, 교각(bridging) 운동, 푸싱(pushing) 운동을 실시하 였다(Fig 1). 각 운동은 갈고리 누운 자세에서 10 회 실시되었으며, 3 세 트 반복하였다. 레그컬1은 공 위에 두 발을 얹고, 천천히 가슴 쪽으로 당긴 후, 다시 펴는 동작이었다(Fig. 1A). 레그컬2는 다리와 엉덩이 사 이에 공을 끼워 배에 힘을 주고 가슴 쪽으로 당긴 후 천천히 제자리 로 돌아오는 동작이었다(Fig. 1B). 교각 운동은 벽에 공을 두고 무릎
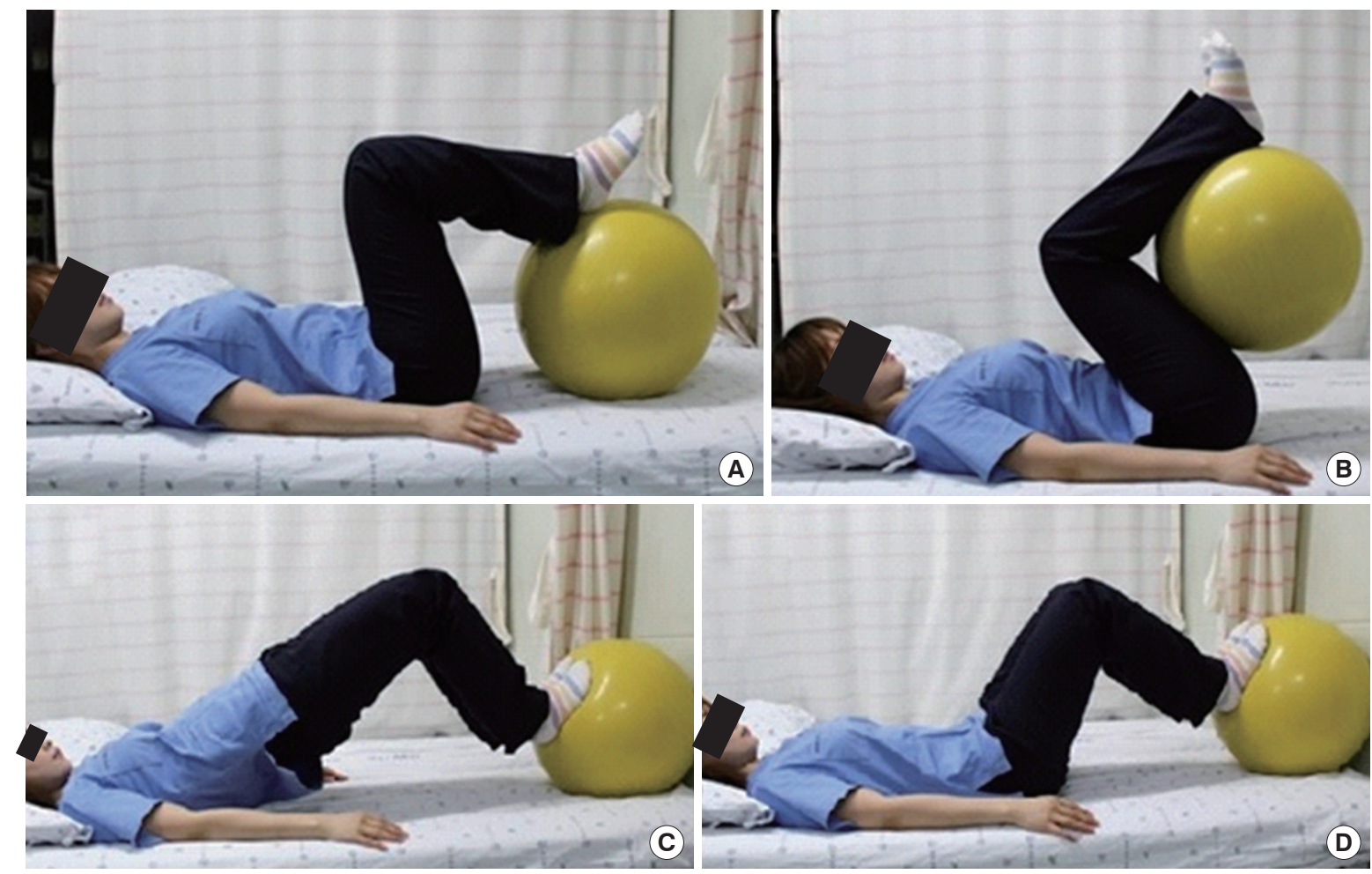

Figure 1. Trunk stabilization exercises with gym ball (A) leg curl 1, (B) leg curl 2, (C) bridging, (D) pushing. 
을 구부려 두 발로 공을 밟은 후, 골반을 바닥에서 들어 올린 후 천천 히 내리는 동작으로 골반을 들어 올렸을 때, 어깨와 골반과 무릎이 일직선이 되도록 하였다(Fig. $1 \mathrm{C}$ ). 마지막으로 푸싱은 벽에 공을 두고 무릎을 90도 정도 구부린 후 공에 발을 두고, 배에 힘을 주어 공을 밟 는 동작이었다(Fig. $1 \mathrm{D}$ ). 각 세트 사이에 1 분의 휴식이 주어졌으며, 각 운동 사이엔 3 분의 휴식이 주어졌다. 실험 기간 동안, 두 그룹 모두 약 물 처치는 통제하지 못하였다.

\section{3. 측정 방법}

연구대상자들은 실험 전과 2주간의 프로그램 적용 후에 어깨뼈 위치 관련 지표와 통증 정도에 대한 측정을 하였다. 통증은 안정시 통증과 야간통증에 대하여 시각적 상사 척도를 사용하여 측정하였다. 어깨 뼈 위치에 대한 측정은 다음의 4 가지 방법을 사용하였다.

\section{1) 복장패임(sternal notch, SN)에서 부리돌기(coracoid process, $\mathrm{CP}$ ) 까지의 거리(DSN_CP}

$\mathrm{D}_{\mathrm{SN} \_\mathrm{CP}}$ 는 안정시 어깨뼈 위치(resting scapular position, RSP)를 평가하 는 필수적인 검사법 중 하나이다. ${ }^{17}$ 값이 클수록 어깨뼈의 들임(retraction) 정도가 큰 것을 의미한다. 측정방법은 환자는 편하게 선 자세에 서 손을 자연스럽게 엉덩관절 옆에 위치시키도록 하고, 머리는 편하 게 정면을 응시하게 한다. 검사자는 표시용 테이프를 이용하여 복장 패임의 중간부위와 부리돌기의 내측면을 표시하고 줄자를 이용하여 거리를 측정한다(Fig. 2A). ${ }^{18}$ 본 측정 방법에 대한 신뢰도와 타당도는 아직 연구되지 않았다.16

\section{2) 세번째 등뼈(3rd thoracic spine, T3)에서 봉우리 후외측각} (posterolateral angle of acromion, PLA)까지의 거리(DT3_PLA)

$\mathrm{D}_{\mathrm{T3} Z \mathrm{PLA}}$ 는 $\mathrm{RSP}$ 를 평가하는 필수적인 검사 중에 하나이며, 값이 클수 록 어깨뼈의 내밈 정도가 큰 것을 의미한다. ${ }^{17}$ 환자는 Fig. $2 \mathrm{~B}$ 와 같은 자세를 취하고, 견봉의 후외측각과 세 번째 흥추 극돌기 중간부위의 거리가 측정된다. 이 측정방법의 측정자내 신뢰도는 0.94 이다. ${ }^{19}$

\section{3) 어깨뼈 지수(scapular index, SI)}

SI는 어깨뼈 위치를 일반화하기 위한 측정 방법으로 임상적으로 어 깨뼈의 위치와 작은 가슴근과의 관계를 반영하는 방법으로 다음과 같이 계산한다. 값이 클수록 어깨뼈가 당김(retraction)된 것이다. ${ }^{18}$

$$
\mathrm{SI}=\left(\mathrm{D}_{\mathrm{SN} \_\mathrm{CP}} / \mathrm{D}_{\mathrm{T} 3_{-} \mathrm{PLA}}\right) \times 100
$$

\section{4) 누운 자세에서의 소흉근(pectoralis minor) 거리( $\left.D_{P M}\right)$}

$\mathrm{D}_{\mathrm{PM}}$ 은 소흥근 길이 혹은 어깨뼈의 기울기를 측정하는 방법으로 값 이 작을수록 어깨뼈가 전방으로 기울었음을 의미한다. 환자는 편하 게 누워서 손을 자연스레 엉덩관절 옆에 위치시키고 손바닥이 천장 을 향하도록 한다. 검사자는 PLA에 표시용 테이프를 이용하여 표시 하고 테이프와 침대까지의 최단거리를 측정한다(Fig 2C). 팔의 자세 는 엎침(pronation), 중립(neutral), 뒤침(supination)에 따라차이가 있으 므로 엎침 상태로 일정한 자세를 유지하도록 한다. 이 측정방법의 측 정자내 신뢰도는 $0.88 \sim 0.94$ 이다. ${ }^{20}$

$\mathrm{D}_{\mathrm{SN} \_\mathrm{CP}}, \mathrm{D}_{\mathrm{T} 3 \text { PLA }}$ 및 $\mathrm{D}_{\mathrm{PM}}$ 은 각각 2 회 반복 측정하여 그 평균값을 사용 하였다.

\section{4. 통계}

수술 전, 연구 대상자의 일반적인 특성(나이, 몸무게, 키, 안정시 통증, 그리고 야간 통증)에 대해서는 그룹 간에 독립 t-검정(independent $\mathrm{t}$ test)를 사용하여 그룹간의 동질성을 검사했다. 수술 후, 프로그램 실 시에 대한 그룹간의 비교는 독립 t-검정을 실시하여 분석하였으며, 각 그룹 내에서 프로그램 전과 후의 차이는 대응 t-검정(paired t-test)을 실시하여 분석하였다. 통계적 유의 수준은 $\alpha=0.05$ 로 설정하였다.

\section{RESULTS}

\section{1. 연구 대상자의 일반적인 특성}

연구 대상자의 일반적인 특성은 Table 1과 같았다. 나이, 몸무게, 키에 대한 각 그룹의 비교는 통계적으로 유의함이 없었다(ps>0.05). 수술
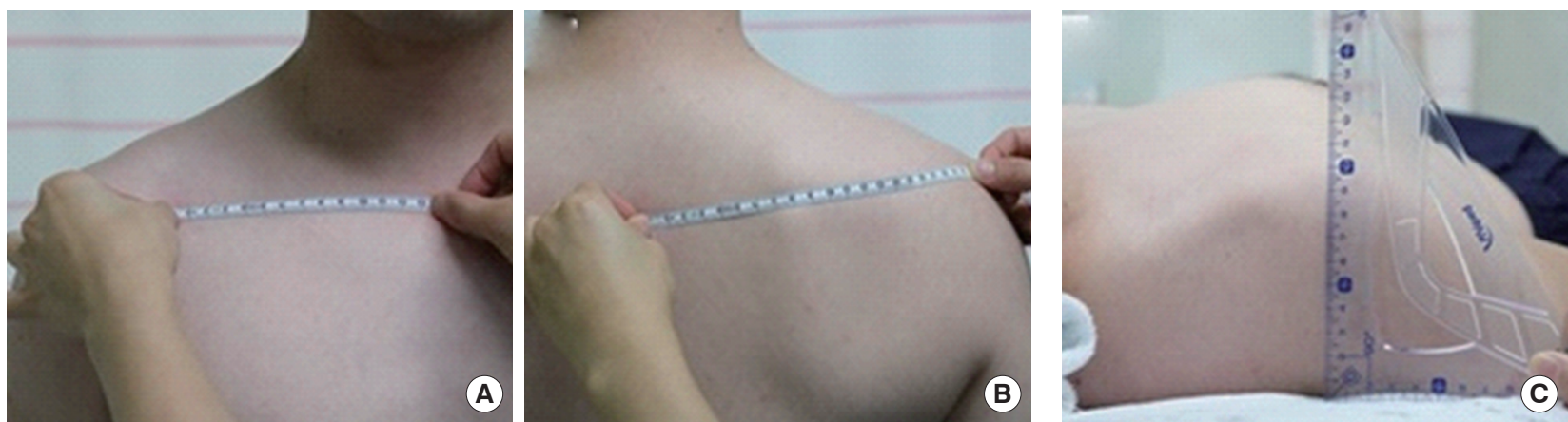

Figure 2. Scapular position assessments (A) $D_{\text {SN_CP, }}(B) D_{T 3 \_ \text {PLA, }}(C) D_{P M}$. 
Table 1. General characteristics of subjects before operation. All values are presented in mean \pm standard deviation except Sex and operation (OP) side presented in number of observation

\begin{tabular}{lcc}
\hline & CTG & SBG \\
\hline Sex (M/F) & $3 / 7$ & $7 / 3$ \\
OP side (Lt/Rt) & $5 / 5$ & $3 / 7$ \\
Age (yr) & $59.20 \pm 10.97$ & $55.00 \pm 10.77$ \\
Height (cm) & $163.80 \pm 9.46$ & $165.10 \pm 6.26$ \\
Weight (kg) & $59.40 \pm 11.34$ & $62.80 \pm 9.88$ \\
Resting pain (VAS) & $6.90 \pm 1.83$ & $7.70 \pm 1.33$ \\
Night pain (VAS) & $6.50 \pm 3.24$ & $7.45 \pm 2.00$ \\
\hline
\end{tabular}

$\mathrm{CTG}=$ conservative treatment group, $\mathrm{SBG}=$ stabilization exercise with gym ball group, VAS = visual analogue scale.

Table 2. Values of scapular position variables before and after 2-week treatment programs

\begin{tabular}{|c|c|c|c|c|}
\hline & & CTG & SBG & p-value \\
\hline \multirow[t]{3}{*}{$D_{S N_{C} C P}(\mathrm{~cm})$} & Before & $13.31 \pm 2.03$ & $12.91 \pm 2.44$ & 0.69 \\
\hline & After & $12.09 \pm 1.11$ & $14.87 \pm 2.26$ & $0.00^{*}$ \\
\hline & $p$-value & $0.01^{*}$ & $0.00^{*}$ & \\
\hline \multirow[t]{3}{*}{$D_{\text {тз_PLA }}(\mathrm{cm})$} & Before & $21.56 \pm 2.36$ & $21.17 \pm 1.96$ & 0.69 \\
\hline & After & $21.04 \pm 2.51$ & $20.15 \pm 1.86$ & 0.38 \\
\hline & $\mathrm{p}$-value & 0.33 & $0.01^{*}$ & \\
\hline \multirow[t]{3}{*}{ SI } & Before & $61.83 \pm 7.51$ & $60.87 \pm 9.07$ & 0.79 \\
\hline & After & $57.91 \pm 6.38$ & $73.91 \pm 10.48$ & $0.00^{*}$ \\
\hline & $\mathrm{p}$-value & $0.04^{*}$ & $0.00^{*}$ & \\
\hline \multirow[t]{3}{*}{$D_{P M}(\mathrm{~cm})$} & Before & $6.55 \pm 1.07$ & $6.48 \pm 0.60$ & 0.85 \\
\hline & After & $7.13 \pm 0.78$ & $4.93 \pm 0.87$ & $0.00^{*}$ \\
\hline & $\mathrm{p}$-value & 0.06 & $0.00^{*}$ & \\
\hline
\end{tabular}

$D_{S N_{C} C P}=$ distance between sternal notch and coracoid process, $D_{T 3 \_ \text {PLA }}=$ distance between 3rd thoracic spine and posterolateral angle of acromion, $\mathrm{SI}=$ scapular index, $\mathrm{D}_{\mathrm{PM}}=$ distance between bottom of table and posterolateral angle of acromion.

전, 안정시 통증과 야간 통증에 대한 두 그룹 간의 통계적 차이도 역 시 발견되지 않았다(ps>0.05).

\section{2. 어깨뼈 위치 변화}

1) 프로그램 적용 전, 어깨뼈 위치에 대한 그룹 간 비교

프로그램 적용 전, 모든 어깨뼈 위치 관련 측정 $\left(\mathrm{D}_{\mathrm{SN} \_C P}, \mathrm{D}_{\mathrm{T} 3 \_\mathrm{PLA}}, \mathrm{SI}\right.$ 및 $\mathrm{D}_{\mathrm{PM}}$ )에 대한 그룹 간 비교에서 $\mathrm{CTG}$ 와 $\mathrm{SBG}$ 는 통계학적으로 유의한 차이가 없었다 $(\mathrm{ps}>0.05)($ Table 2$)$.

\section{2) 프로그램 완료 후, 어깨뼈 위치에 대한 그룹 간 비교}

2주간의 프로그램 완료 후, $\mathrm{D}_{\mathrm{SN}_{-} \mathrm{CP}}$ 에 대한 그룹 간 비교에서 $\mathrm{SBG}$ 는 CTG에 비해 유의하게 컸다 $(\mathrm{p}<0.05)\left(\right.$ Table 2). $\mathrm{D}_{\text {T3_PLA }}$ 에 대한 그룹 간

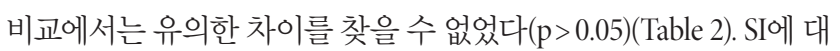
한 그룹 간 비교에서는 $\mathrm{SBG}$ 는 $\mathrm{CTG}$ 에 비해 유의하게 컸다 $(\mathrm{p}<0.05)$
Table 3. Values of VAS before and after 2-week treatment programs

\begin{tabular}{lcccccccc}
\hline & \multicolumn{3}{c}{ Rest pain (VAS) } & & \multicolumn{3}{c}{ Night pain (VAS) } \\
\cline { 2 - 3 } & Before & After & p-value & & Before & After & p-value \\
\hline CTG & $6.05 \pm 0.92$ & $6.05 \pm 1.32$ & 1.00 & & $5.15 \pm 2.55$ & $5.65 \pm 1.51$ & 1.00 \\
SBG & $5.70 \pm 0.85$ & $3.85 \pm 1.05$ & $0.00^{*}$ & & $5.55 \pm 1.16$ & $3.95 \pm 1.11$ & $0.00^{*}$ \\
p-value & 0.39 & $0.00^{*}$ & & & 0.65 & $0.01^{*}$ & \\
\hline
\end{tabular}

(Table 2). $\mathrm{D}_{\mathrm{PM}}$ 에 대한 에 그룹 간 비교에서는 SBG는 CTG에 비해 유의 하게 작았다 $(\mathrm{p}<0.05)($ Table 2).

\section{3) CTG의 프로그램 전·후 비교}

$\mathrm{D}_{\mathrm{SN} \_\mathrm{CP}}$ 와 $\mathrm{SI}$ 에 대한 프로그램 전·후 비교에서 프로그램 후에 유의하 게 작아졌다 $(\mathrm{ps}<0.05)(\mathrm{Table} 2) . \mathrm{D}_{\mathrm{T} 3 \_\mathrm{PLA}}$ 와 $\mathrm{D}_{\mathrm{PM}}$ 에 대한 프로그램 전·후 비교에서 유의한차이가 발견되지 않았다(ps>0.05)(Table 2).

\section{4) SBG의 프로그램 전·후 비교}

모든 어깨뼈 위치 관련 측정( $\mathrm{D}_{\text {SN_CP, }} \mathrm{D}_{\mathrm{T} 3 \text { _PLA, }} \mathrm{SI}$ 및 $\left.\mathrm{D}_{\mathrm{PM}}\right)$ 에 대한 프로그 램 전·후 비교에서 훈련 전에 비해 훈련 후 평균값은 유의한 차이가 있었다 $(\mathrm{ps}<0.05)($ Table 2$)$.

\section{3. 통증의 변화}

1) 안정시 통증 변화에 대한 그룹 간 및 그룹 내의 비교 프로그램 시작 전, 안정시 통증에 대한 그룹 간 비교에서 CTG와 SBG 는 통계적으로 유의한 차이가 없었으나( $\mathrm{p}>0.05)$, 프로그램 완료 후에 는 SBG가 CTG에 비해 유의하게 낮은 값을 보였다 $(\mathrm{p}<0.05)($ Table 3).

$\mathrm{CTG}$ 의 안정시 통증에 대한 그룹 내 차이를 비교한 결과, 프로그램 전, 후에 따른 통증은 유의한 차이가 없었다(p>0.05)(Table 3). 하지만, $\mathrm{SBG}$ 는 프로그램 전에 비해 완료 후에 통증이 유의하게 낮아졌다 $(\mathrm{p}<0.05)($ Table 3$)$.

\section{2) 야간통증 변화에 대한 그룹 간 및 그룹 내의 비교}

프로그램 시작 전, 야간통증에 대한 그룹 간 비교에서 두 그룹은 통 계적으로 유의한 차이가 없었으나( $\mathrm{p}>0.05)$, 프로그램 종료 후에는 $\mathrm{SBG}$ 가 CTG에 비해 유의하게 낮은 값을 보였다 $(\mathrm{p}<0.05)($ Table 3).

CTG의 야간통증에 대한 그룹 내 비교 결과, 프로그램 전과 후의 통증은 유의한 차이가 없었다( $\mathrm{p}>0.05$ )(Table 3). 반면, SBG의 야간통 증에 대한 그룹 내 차이는 유의하였고 $(\mathrm{p}<0.05)$, 이는 프로그램 후에 통증이 유의하게 낮아졌음을 보여준다(Table 3).

\section{DISCUSSION}

본 연구는 관절경하 돌림근띠 봉합술을 시행한 환자에게 수술 후 초 
기 단계에 짐볼을 이용한 몸통 안정화 운동 적용이 어깨뼈 위치와 통 증에 어떠한 영향을 미치는지 알아보았다. 이를 위해, 짐볼을 이용한 몸통 안정화 운동을 적용한 그룹과 보존적 치료를 적용한 그룹으로 나눠 2주간의 치료 적용 후, 수술 측 어깨의 어깨뼈 위치와 통증 변화 를 측정하여 비교하여 보았다. 연구 결과를 요약하면 다음과 같다. 첫 째, 2 주간의 프로그램 완료 후, CTG의 $\mathrm{D}_{\mathrm{SN} \_\mathrm{CP}}$ 는 줄어들었으나, SBG에 서는 커졌다. 이는 보존적 치료에서는 어깨뼈 들임이 줄어들었고, 짐 볼을 이용한 몸통 안정화 운동은 어깨뼈 들임을 크게 만들었음을 의 미한다. 둘째, $\mathrm{CTG}$ 는 $\mathrm{D}_{\mathrm{T} 3 \_\mathrm{PLA}}$ 에 영향을 주지 않았으나, $\mathrm{SBG}$ 은 줄였다. 이는 짐볼을 이용한 몸통 안정화 운동이 어깨뼈 내밈을 감소시켰다 는 것을 의미한다. 셋째, 이러한 $\mathrm{D}_{\mathrm{SN}_{-} \mathrm{CP}}$ 와 $\mathrm{D}_{\mathrm{T} 3 \_\mathrm{PLA}}$ 의 변화는 CTG의 $\mathrm{SI}$ 를 감소시켰으며, $\mathrm{SBG}$ 의 SI를 증가시켰다. 다시 말해, 보존적 치료는 어깨뼈 내밈을 증가시켰고, 짐볼을 이용한 몸통 안정화 운동은 어깨 뼈 들임을 증가시켰음을 의미한다. 넷째, $\mathrm{CTG}$ 는 $\mathrm{D}_{\mathrm{PM}}$ 에 변화를 주지 못하였으나, SBG는 어깨뼈의 전방 기울기를 감소시켰다. 이는 짐볼을 이용한 몸통 안정화 운동이 어깨뼈의 기울기 정렬에도 영향을 주었 음을 의미한다. 마지막으로 안정시 통증 및 야간통 모두 SBG가 CTG 에 비해 더 큰 통증 감소의 효과를 가져왔다. 다음에서 본 연구에서 나타난 어깨뼈 위치와 통증 변화에 대해 논의를 해보고자 한다.

먼저, 본 연구에서 가장 큰 발견은 짐볼을 이용한 몸통 안정화 운 동이 어깨뼈의 위치 변화를 가져왔다는 점이다. 구체적으로 본 연구 의 짐볼을 이용한 몸통 안정화 운동은 어깨뼈를 들임하고, 어깨뼈의 전방 기울임 감소를 만들어 낸 것으로 확인되었다. 이러한 위치 변화 는 어깨 봉우리 아래 공간을 확보하여 돌림근띠의 충돌을 감소시키 는 위치로 어깨뼈의 정렬 상태가 변했다는 것을 의미한다. ${ }^{7,21}$ 확보된 어깨 봉우리 아래 공간은 돌림근띠에 가해지는 충돌과 자극을 줄이 면서, 통증을 감소시킨 것으로 보인다. $\mathrm{SBG}$ 의 경우, 안정시와 야간 통 증 모두 의미 있게 감소했는데, 이 두 가지 통증 모두 감소했다는 것 은 구조적 변화에 의한 것임을 암시한다.

그렇다면 왜 짐볼을 이용한 몸통 안정화 운동이 어깨뼈의 정렬 상 태를 변화시킨 것일까? 본 연구에서 사용되었던 볼을 이용한 몸통 안 정화 운동은 레그컬, 교각운동, 푸싱운동으로 몸통 안정성 향상에 초점이 맞춰진 운동들이다. 이런 동작과 함께 볼을 사용하여 불안정 한 지지면을 만들어 몸통근 활성이 높여주었다. ${ }^{22,23}$ 교각운동을 제외 한 모든 운동들이 수행될 때, 등을 지속적으로 바닥에 붙여서 하지에 서의 움직임이 잘 수행될 수 있도록 하여야 한다. 교각운동이 수행될 때는 가슴우리 및 목의 뒤쪽이 바닥에 밀착되어 동일한 역할을 하게 된다. 다시 말해, 본 연구에서 사용된 짐볼을 이용한 몸통 안정화 운 동은 목과 가슴우리, 허리까지 이르는 모든 몸통의 안정성이 요구된 것이다. 특별히 하지의 움직임에 안정성을 제공하기 위해, 몸통을 바 닥에 밀착시키는 힘에 의해 어깨뼈 들임 근육이 더욱 활성화되었을
것이다. 본 연구에서 발견된 SBG의 어깨뼈 들임의 증가와 전방 기울 기 감소는 이러한 기전에 의해 발생되었을 것으로 생각된다.

반면 보존적 치료는 어깨뼈 들임을 감소시킨 것으로 나타났다. 이 러한 어깨뼈의 위치 변화는 오히려 어깨 봉우리 아래 공간을 좁히는 원인이 될 수 있어 나쁜 변화이다. 돌림근띠 봉합술 후 외전보조기 (shoulder immobilizer)를 착용하게 되는데, 본 연구에 참여한 연구대 상자들도 동일하게 적용 받았다. 외전보조기는 파열의 크기에 따라 4-6주간 착용하는데, 착용기간이 길어질수록 어깨와 가슴우리에 둥 근 어깨와 같은 자세를 가져올 수 있는 것으로 알려져 있다.5,24 즉, 본 연구에서 나타난 CTG의 들임 감소는 둥근 어깨의 과정으로 생각되 며, 들임 감소와 내밈 증가는 어깨 봉우리 아래 공간을 좁히는 원인이 될 수 있기 때문에 돌림근띠 봉합술 이후에 보존적 치료의 지속적 적 용은 적절하지 못한 것으로 생각된다. 덧붙여, 통증에서도 $\mathrm{CTG}$ 는 치 료 전과 후에 변화를 가져오지 못하였다. 이는 SBG와 달리 어깨뼈의 정렬에 긍정적 변화가 없었기 때문으로 생각된다.

본 연구는 관절경하 돌림근띠 봉합술 환자에게 보존적 치료는 어 깨뼈의 정렬에 부정적 결과를 가져올 수 있으며, 조기에 시행된 짐볼 을 이용한 몸통 안정화 운동은 어깨뼈의 바른 정렬과 통증 감소를 가 져올 수 있음을 보여주었다. 짐볼을 이용한 몸통 안정화 운동에 수반 된 이러한 긍정적 효과들은 어깨뼈의 바른 정렬을 통한 어깨 봉우리 아래 공간 확보에 기인하는 것으로 생각된다. 이를 통하여 통증 감소 와 더불어 돌림근띠의 재손상을 방지하는 효과를 가져올 수 있음을 보여준다. 이처럼 본 연구 결과는 어깨 돌림근띠 봉합술 환자의 통증 감소와 어깨뼈 정렬 변화를 통해 어깨 재활의 최종 목표인 기능성을 획득하기 위해 몸통 안정화 운동이 재활프로그램 조기에 활용할 것 을 제안한다. ${ }^{1,25,26}$

본 연구에서는 짐볼을 사용한 몸통 안정화 운동을 시행하였는데, 도구를 사용하지 않는 몸통 안정화 운동에서도 동일한 결과가 나타 날 수 있는지 심화 연구가 필요할 것이다. 본 결과가 나타날 수 있는 여러 요소들 중에서 어깨뼈 위치에 관해서만 살펴보았다는 것은 본 연구의 제한점으로 남는다. 또한 증례의 수가 비교적 부족하여 연구 결과를 일반화하기 어려운 점이 있었으며, 평가 기간이 수술 후 약 3 개월 시점으로 국한되어 장기적 추세 변화를 보지 못했던 점은 제한 점이다. 향후 이러한 점이 보완된 연구가 필요할 것이라 생각된다.

\section{REFERENCES}

1. Kuhn JE, Dunn WR, Sanders R et al. Effectiveness of physical therapy in treating atraumatic full-thickness rotator cuff tears: a multicenter prospective cohort study. J Shoul Elb Surg. 2013;22:1371-9.

2. Neer CS. Anterior acromioplasty for the chronic impingement syndrome in the shoulder: a preliminary report. J Bone Joint Surg. 1972;54:41-50. 
3. Yamamoto A, Takagishi K, Kobayashi T et al. The impact of faulty posture on rotator cuff tears with and without symptoms. J Shoul Elb Surg. 2015;24:446-52.

4. McElvany MD, McGoldrick E, Gee AO et al. Rotator cuff repair: published evidence on factors associated with repair integrity and clinical outcome. Am J Sports Med. 2015;43:491-500.

5. Cools A, Witvrouw E, Declercq G et al. Scapular muscles recruitment pattern: trapezius muscle latency in over hand athletes with and without impingement symptoms. Am J Sports Med. 2003;31:542-9.

6. Barrett E, O'Keeffe M, O'Sullivan K et al. Is thoracic spine posture associated with shoulder pain, range of motion and function? A systematic review. Man Ther. 2016;26:38-46.

7. Kibler WB. The role of the scapula in athletic shoulder function. Am J sports Med. 1998;26:325-37.

8. Akuthota V, Ferreiro A, Moore T et al. Core stability exercise principles. Curr. Sports Med. Rep. 2008;7:39-44.

9. Jung YJ, Jung KM. The effect of scapula setting intervention on the function of upper extremity andwalking in the patients with stroke. Neurotherapy. 2013;17:39-44.

10. Kim GH, Choe HS, Lee HI et al. The effects of scapular stabilization exercising on dynamic standing balance in stroke patients. J Korean Soc Phys Ther Vol. 2014;26:15-20.

11. Burkhart SS, Adams CR, Schoolfield JD. A biomechanical comparison of 2 techniques of footprint reconstruction for rotator cuff repair: the SwiveLock-FiberChain construct versus standard double-row repair. Arthroscopy. 2009;25:274-81.

12. Keener JD, Galatz LM, Stobbs-Cucchi G et al. Rehabilitation following arthroscopic rotator cuff repair: a prospective randomized trial of immobilization compared with early motion. J Bone Joint Surg. 2014;96:11-9.

13. Fermont AJ, Wolterbeek N, Wessel RN et al. Prognostic factors for successful recovery after arthroscopic rotator cuff repair: a systematic literature review. J Ortho Sports Phys Ther. 2014;44:153-63.

14. Ko DS, Moon KI, Park WS. The effects of shoulder exercise program including scapula strengthening exercise after arthroscopic rotator cuff re- pair. KSSPT. 2011;7:64-8.

15. Lee MJ, Kim SY, Shim JK. Comparison of shoulder range of motion, pain, function, scapular position between breast cancer surgery and shoulder surgery female patients. Phys Ther Korea. 2015;22:9-18.

16. Jung YM, Choi JD. The relationship between resting scapular position and pain level in unilateral shoulder pain. Phys Ther Korea. 2010;17:2532.

17. Nijs J, Roussel N, Struyf F et al. Clinical assessment of scapular positioning in patients with shoulder pain: state of the art. J Manipulative Physio Ther. 2007;30:69-75.

18. Bostad JD. Resting position variables at the shoulder: evidence to support a posture-impairment association. Phys Ther. 2006;86:549-57.

19. Gibson MH, Goebel GV, Jordan TM et al. A reliability study of measurement techniques to de- termine static scapular position. J Orthop Sports Phys Ther. 1995;21:100-6.

20. Nijs J, Roussel N, Vermeulen K et al. Scapular positioning in patients with shoulder pain: a study examining the reliability and clinical importance of 3 clinical tests. Arch Phys Med Rehabil. 2005;86:1349-55.

21. Mottram SL. Dynamic stability of the scapula. Man Ther. 1997;2:123-31.

22. Vera-Garcia FJ, Grenier SG, McGill SM. Abdominal muscle response during curl-ups on both stable and labile surfaces. Phys Ther. 2000;80:564-9.

23. Youdas JW, Coleman KC, Holstad EE et al. Magnitudes of muscle activation of spine stabilizers in healthy adults during prone on elbow planking exercises with and without a fitness ball. Physiother Theory Pract. 2017;33:1-11.

24. Hermans V, Spaepen A. Perceived discomfort and electromyographic activity of the upper trapezius while working at a VDT station. Int J Occup Saf and Ergon. 1995;208-14.

25. Cuff DJ, Santoni BG. Rehabilitation strategies after rotator cuff repair: how to optimize outcomes. Techniques in Shoulder \& Elbow Surgery. 2016;17:149-52.

26. Chang KV, Hung CY, Han DS et al. Early versus delayed passive range of motion exercise for arthroscopic rotator cuff repair: a meta-analysis of randomized controlled trials. Am J Sports Med. 2015;43:1265-73. 